\title{
A multi-model approach to the simulation of large scale karst flows
}

\author{
C. Makropoulos ${ }^{\mathrm{a}, *}$, D. Koutsoyiannis ${ }^{\mathrm{b}}$, M. Stanićc ${ }^{\mathrm{c}}, \mathrm{S}$. Djordjević ${ }^{\mathrm{a}}$, D. Prodanovic ${ }^{\mathrm{c}}$, T. Dašićc ${ }^{\mathrm{c}}$, S. Prohaska $^{\mathrm{d}}$, \\ Č. Maksimović ${ }^{\mathrm{e}}$ and H. Wheater ${ }^{\mathrm{e}}$
}

\begin{abstract}
${ }^{a}$ Centre for Water Systems, University of Exeter, UK, ${ }^{b}$ Department of Civil Engineering, National Technical University of Athens, Greece ${ }^{c}$ Faculty of Civil Engineering, University of Belgrade, Serbia ${ }^{d}$ Jaroslav Černi Institute, Belgrade, Serbia ${ }^{\mathrm{e}}$ Department of Civil and Environmental Engineering, Imperial College London, UK
\end{abstract}

\begin{abstract}
The possible effects of water transfer through the tunnel Fatničko Polje - Bileća Reservoir on the hydrologic regime of the Bregava River located in Eastern Herzegovina, in an area characterised by a predominantly karstic terrain, are studied. Three different simulation models of the area were developed and their predictions compared under a range of current and future hydrological and operational management conditions. These are based on a range of modelling approaches from a simplified conceptual approach to a quasi-physically based one. Despite the large complexity of the natural system, the models gave good fits to existing flow data with the most simplified model providing the closest agreement to historical flows. Calibrated models were used to study the possible effects of the intervention under a range of operational scenarios and identify the sources of the associated uncertainties. The results of the work suggest that the system of tunnels in question has a favourable effect in reducing flood hazard in the area, thus liberating scarce land resources for agriculture, and in reduction of flows in the Bregava River, especially the high flows. It is also suggested that a significant reduction in the uncertainty of modelling the karstic environment can be achieved by an appropriate, complementary combination of modelling approaches viewed as a multimodel ensemble.
\end{abstract}

Keywords: Karstic hydrology, water resources, physically-based modelling, conceptual modelling, complexity, multi-modelling

\footnotetext{
* Corresponding author. Address: Centre for Water Systems, School of Engineering, Computer Science and Mathematics, University of Exeter, EX4 4QF UK. Tel. ++01392- 264049. Email: c.makropoulos@exeter.ac.uk
} 


\section{Introduction}

\subsection{General}

This study investigates the possible effects of a water transfer scheme on the hydrologic regime of the Bregava River in Eastern Herzegovina, in an area characterised by a predominantly karstic terrain (complete details, including an extensive presentation of data, models and results is included in ICCI (2004), available online). The system is complex, and data are limited, hence the study uses different modelling approaches to assess the robustness of management decisions in the face of system uncertainty. Since the primary objective was to assess the impact of the water transfer scheme on the hydrologic regime, given limited system information, the intercomparison of methods, focussed on criteria for the overall behaviour of the models, rather than on their performance with respect to the detail of the system representation.

Flow in the karstic zone represents one of the most complex hydrologic phenomena. The area studied is characterised by karstic depressions or valleys (poljes) connected by a system of karstic conduits. Poljes are flat and fertile, usually a few hundred meters wide and one or two kilometers long or more. Water enters the poljes through karstic springs and leaves them through swallow holes (ponors) which represent the exit and entrance of karstic conduits, respectively. The function of karstic conduits (including quantity and direction of flow) is complex and subject to extreme seasonal variations, including flow reversals (for example Albéric, 2004). The relevant literature on conceptualising karstic conduits, particularly when aquifer hydraulic parameters are limited, is growing (see for example Eisenlohr et al., 1997) and recent work has concentrated, inter alia, on the possibility of extracting quantitative information about the geometric and hydraulic aquifer parameters in karstic systems from spring hydrograph analysis (Kovacs et al., 2005). In any case, it is suggested that the complexity and uncertainty inherent in the 
representation of the karstic environment, particularly where data are scarce and may be unreliable, have significant implications in managing karstic aquifers and their water resources, particularly in terms of their vulnerability (Andreo et al., 2006; Vias et al., 2006).

\subsection{Background to the study}

The case study area is characterized by the existence of surface and underground karst phenomena, with little arable land. This study focused on two major catchments of the area, which are hydraulically connected through karstic conduits (Figure 1): (a) the Trebišnjica River which is the biggest sinking river in Europe and regularly floods its poljes, rendering some of them unsuitable for human settlements and limiting possible agricultural exploitation and (b) the Bregava River, which in addition to its direct (topographic) catchment, is mainly fed through springs which originate from a karstic field (the Dabarsko polje - DP). Although the Fatničko polje (FP) belongs to the Trebišnjica catchment, seasonal water transfers take place between the FP and the Bregava catchment, regulated by a "bottleneck" in the karst downstream of the Dabarsko polje which limits the peak flows to the capacity of an underground system of fissures and larger karstic conduits (Figure 1). The study dealt with the upstream part of the Bregava catchment (near the hydrometric station Do, near Stolac, see Figure 1). Downstream of Do, the river flows mostly underground in periods of low discharge.

In the late 1950s a water management plan for the area was conceived, with the original objectives of hydropower generation and flood alleviation. This has evolved in a number of stages, involving the construction of tunnels, dams, and the installation of turbines. 
While part of the system downstream of the Bileća Reservoir (BR) is currently in an advanced stage of development, in the upstream region, a tunnel DP-FP has been constructed while a tunnel FP-BR is about to be constructed.

Figure 1. General outline of the area and current level of development of the whole Trebišnjica system. Thick lines are catchment boundaries and arrows indicate main karstic flow routes. Dashed lines represent tunnels, full dots represent springs while half-full dots represent ponors. Hydroelectric stations are marked as squares. The Do station is located upstream from Stolac, close to the catchment boundary.

The two tunnels, at different development stages, form the hydro-system, the impacts of which this paper attempts to study. Some basic characteristics of those two tunnels are:

- Tunnel Dabarsko Polje to Fatničko Polje (DP-FP): The tunnel is approximately 3.2 $\mathrm{km}$ long and was constructed in 1986. The flow is regulated at the downstream end of the tunnel by a vertical sluice gate, which is operational. At present (2004 - before the construction of the tunnel between Fatničko Polje and Bileća Reservoir) the operational rule requires that the gate should be closed only when the water level in Fatničko Polje is higher than in Dabarsko Polje.

- Tunnel Fatničko Polje to Beleća Reservoir (FP-BR): The tunnel is much longer than DP-FP (approximately $15 \mathrm{~km}$ ) and also has a flow regulation gate at its downstream end. Under the present operational management framework it is to be kept open at all times. 


\subsection{The problem}

Due to the existence of karstic conduits, linking DP and FP with both catchments, the operation of the two tunnels effectively links the two catchments and thus an assessment of the impact of their operation was needed. In particular a concern was that the operation of the tunnels would have adverse effects on the Bregava River, by lowering the low flows, and thus contributing to increased water scarcity in the Bregava catchment.

\subsection{The approach}

Evaluating the system's response was a particularly challenging process, in terms of data availability, data and system uncertainty, understanding of system operation, system modelling, results comparison and interpretation. The overall system is highly complex and poorly understood. Interventions in one part can have hard-to-quantify and widely variable effects on remote locations linked through underground karstic conduits. Furthermore, data were scarce and to a large extent unreliable, particularly since the regular monitoring programme was disrupted by the 1991-95 civil war. The approach adopted was to employ a range of models, of varying complexity, developed by independent modelling teams and then critically evaluate and interpret the results to quantify the overall uncertainty of the study. The main thesis behind this approach was that multiple descriptions of real-world phenomena, each expressed using a different modelling approach, can provide a more thorough understanding than if a single representation were used (Stanger, 2000) and comparisons between them can yield results that can be instructive, both in terms of the (complex) system at hand and of the models themselves. In terms of hydrologic modelling in particular, Smith et al. (2004) and Reed et al. (2004), for example, used twelve different distributed and lumped hydrologic models to explore issues of optimal levels of spatial disaggregation, 
calibration effect on model performance and level of model complexity required. The approach adopted is relevant not only to the particular problem at hand, but to karstic systems modelling in general, due to their inherent uncertainty, and constitutes an example of the developing domain of multi-modelling applied to a problem of considerable geographic and political importance.

\section{Catchment characteristics}

Geologically, the case study area is a typical example of holokarst, comprised entirely of soluble carbonate rocks. There are numerous poljes of varying size in this region. These are elongated in shape, with their longer axes following geological structures, particularly the main overthrust direction from NW to SE (see e.g. Figure 2). Almost all poljes of the region are flooded during the winter, when the inflow capacity of the ponors is lower than the quantities of water discharged into the poljes (through karstic springs and surface water courses). There are two major rivers in the broader area, Neretva and Trebišnjica, and a number of smaller surface water courses, most of them having flows only in the winter period of high precipitation. Water flows predominantly underground: it infiltrates in the upper parts of the catchment and discharges as springs which occur at the base of karst system. The ponors are situated at the southern edge of the poljes, while the springs are situated at the northern edge (Avdagić, 1975).

Figure 2. Simplified hydrogeological map of Bregava source spring drainage area

1. Catchment area, 2. Ponor, 3. Underground communication detected by a dry test, 4. Permanent or intermittent source spring, 5. General directions of underground water circulation, 6. Dry valley, 7. Synclinal axis, 8. Reverse fault, 9. Zone off bifurcation, 10. Impervious Tertiary sediments 
To analyse the Bregava river regime, the area of interest is extended beyond its topographic catchment area, to include the catchment area of the Trebišnjica springs, since part of the water from Fatničko Polje also discharges into the Bregava springs (Figure 2). The zones of the greatest underground flow are mainly just above the base of karstification and converge towards the Trebišnjica spring zone (Figure 2). The existence of flow paths below the base level of karstification cannot be excluded, but they would be rare and of limited capacity. Below the lowest water table level the porosity decreases abruptly. The base of karstification and the lowest water table level approximately coincide (Milanović, 1986).

\subsection{The Trebišnjica River Catchment}

The spring zone of the Trebišnjica River is one of the biggest in terms of capacity in the entire region. A broad karst aquifer, fed by a catchment area of $1100 \mathrm{~km}^{2}$, discharges through this spring zone. The annual average flow of the Trebišnjica River, in the region of the Grančarevo Dam, is $80 \mathrm{~m}^{3} / \mathrm{s}$, and the largest recorded flow is $864 \mathrm{~m}^{3} / \mathrm{s}$. The entire catchment area is characterized by high infiltration capacities. In addition, focussed infiltration of the karst groundwater system occurs at the Gatačko and Fatničko poljes, with intake capacities of approximately 160 and $120 \mathrm{~m}^{3} / \mathrm{s}$ respectively. The result of this infiltration is the rapid response of groundwater levels and pressurised flow in the karst conduits.

\subsection{Bregava River Catchment}

The catchment area of the Bregava spring zone (Figure 2) is about $396 \mathrm{~km}^{2}$. The average measured discharge of the spring zone is $17.5 \mathrm{~m}^{3} / \mathrm{s}, 59 \mathrm{~m}^{3} / \mathrm{s}$ at maximum. The catchment 
area is divided by a deep hydrogeological barrier (impervious Tertiary sediments) beneath the Dabarsko Polje, into two hydrogeological units. One is the direct topographic catchment area, which covers about $60 \%$ of the total catchment area. The other part, known as the indirect catchment area, contributes some flow to the Bregava system part of the time and consists of the catchment area of the Dabarsko Polje.

\section{Data}

\subsection{Meteorology and climatology}

All available historical climate data have been compiled for the period 1925-2003, for 51 meteorological stations located in the Trebišnjica and Bregava River catchments. Data include monthly temperature, precipitation and other climatological variables. Time series were compiled for eleven meteorological stations from 1961 to 2003. A longer period (from 1925) was available only for one station. The period from 1951-1986 was considered the best data source, particularly for daily precipitation data. Daily evaporation has been computed using the FAO Penman method (Allen et al., 1998).

\subsection{Topography and Geographical Information System (GIS) datasets}

A Digital Elevation Model (DEM) was developed to enable the checking of the stagevolume curves of Dabarsko and Fatničko poljes. Due to the nature of this objective, the primary concern was the map's vertical resolution. For the development of the DEM, the most detailed maps available (1:25000) were digitised and auxiliary data were included from paper maps of scale 1:50000. The 1:25000 maps included $10 \mathrm{~m}$ contour lines, with $5 \mathrm{~m}$ contour lines in the lower parts of the karstic fields, and with few spot heights. The schematic map of the Trebisnjica system, which was used for modelling, was re-sampled, geo-referenced, and loaded into a database and the catchment area was digitised on 
screen. Horizontal positional error was assessed to be less than $5 \mathrm{~m}$. Vertical resolution was assessed to be better than $5 \mathrm{~m}$ in flat areas. The whole catchment area was defined using a grid size of $30 \mathrm{~m}$, while two detailed DEMs of Dabarsko and Fatničko poljes were created with $20 \mathrm{~m}$ grid size. The DEM was corrected for small errors in slope along the vertices of triangles on the break lines, using the "burn-in" procedure, so natural terrain features were preserved. The stage-volume curves produced from the DEM allowed for a close match with measured data and were thus used by the modelling teams.

\subsection{Surface and groundwater flows}

Flow and groundwater level data were collected for two periods: Period A: 1/1/196131/10/1986 which corresponds to natural conditions of the hydrosystem and Period B: $1 / 11 / 1986-31 / 12 / 2003$ which corresponds to partly managed conditions as the DP-FP tunnel was operated during that period. Details of the data and their use are provided in following sections.

\section{Modelling}

\subsection{Strategy and Objectives}

The modelling strategy employed was the use of three different modelling approaches, each of which may contain more than one model configuration or implementation. These included different system conceptualisations and temporal and spatial discretisation as well as different solution algorithms so that the ensemble of modelling results implicitly represents a measure of the uncertainty of the modelling problem at hand. The modelling approaches were developed, calibrated and run independently and can be characterised as quasi-physically based, black box and conceptual, respectively, following the definitions of Wheater et al. (1993). The modelling target was the unbiased assessment of the effect 
of water transfer from Dabarsko to Fatničko Polje and from Fatničko Polje to the Bileća Reservoir on the hydrologic regime of the Bregava River (Figure 2).

The hydrometric station Do in the upstream part of Bregava (just upstream of Stolac in Figure 1) was used as the reference point for measuring predicted impact to the Bregava spring zone. The fact that the quality of data was modest (several monitoring stations that used to be operational in the area are currently abandoned and measurements discontinued) has to be taken into account when assessing the accuracy and uncertainty of the developed models.

\subsection{Modelling approaches}

\subsubsection{Quasi-physically based modelling}

In this approach the system is conceptualised as a series of links and reservoirs, represented by two alternative models: a simple model, based on quasi-steady state hydraulic simulation treating the problem as a system of reservoirs, and a detailed model, based on full-dynamic simulation of flow in the assumed network of tunnels and reservoirs. Flow in the unsaturated zone is assumed to be primarily vertical and is modelled based on Richards' equation. Results of the unsaturated zone simulation were used as input hydrograph to both models mentioned above. A brief description of the unsaturated zone model (UNSAT) and the two network models follows:

(a) UNSAT: The model (Pokrajac et al., 2006) simulates vertical water movement and leakage from the unsaturated zone based on Richards' equation, under the assumption that recharge to the karst can be represented as an equivalent porous medium. This is clearly an approximation which does not take into account the difference between slow 
and rapid recharge. Richards' equation is solved for a set of vertical soil columns. Boundary conditions are defined in the form of an upper boundary flux (at the soil surface) and free drainage for the bottom boundary condition. Actual evaporation is determined as a function of potential evaporation and soil moisture, and evaporation losses are limited by the ability of the soil to transport water from deeper soil layers. In the case where rainfall minus potential evaporation exceeds infiltration capacity only a part of the precipitation infiltrates and surface runoff is generated.

(b) Simple routing model: This model is based on quasi-steady state hydraulic simulation, treating the problem as a system of reservoirs. The simplified physicallybased model is conceptualised as a set of nodes (reservoirs and channel junctions) and links (pipes, channels, weirs or orifices). Flow can occur in both directions (positive and negative). Each node can have its own catchment area, and therefore its own inflow as a result of leakage from the unsaturated zone. A set of ordinary differential equations is solved simultaneously for the whole network. The results of the simulation are water levels for each node and discharges for each connection.

(c) Detailed routing model (SIPSON): This detailed model is based on full-dynamic simulation of free-surface and pressurized flow in the assumed network of tunnels and reservoirs. The topology of the underground network was defined such that the tunnels coincide with the identified flow paths. Characteristics of network elements were first assumed, and then varied in a number of numerical experiments. The geometry of manmade tunnels and of surface reservoirs (i.e. poljes) was taken as known. 
The SIPSON simulation model is an integral part of the 3DNet software (Djordjevic et al., 2003). Simultaneously for all network elements, SIPSON solves four groups of equations: the continuity equations for nodes (reservoirs or point-type junctions), the St. Venant equations of flow in tunnels, the energy conservation equations for nodes and tunnel ends and equations of flow through structures such as weirs. The solution algorithm is based on the Euler modified method (node continuity equation), the Preissmann four-point implicit finite difference method (tunnel flow equations), the Friazinov algorithm (temporary reduction of the system of tunnel flow equations) and the conjugate gradient method (system of node continuity equations). Details of these procedures are given by Djordjević et al. (2004).

The detailed model typically had two reservoirs connected by one or two tunnels. The network was looped (because water from Dabarsko polje could reach the outlet to Bregava either directly or via the tunnel to Fatničko polje), with three outlets. For a given inflow to the system, calibration of the detailed model was more sensitive to tunnel diameters (that directly influence dynamics of surcharging of these links) than to parameters such as roughness or weir discharge coefficients. In addition to the two surface nodes (Dabarsko polje and Fatničko polje) that were described in the model with their known volumes/areas, significant storage was also assigned to some internal (underground) system nodes.

For both the simple and detailed model the hydrosystem was decomposed into three (geologically and physically different) subsystems. The system's decomposition in space can be seen in Figure 3.

Figure 3. System decomposition in space for the quasi-physically based model 


\subsubsection{The black-box/transfer function model}

The black-box/transfer function model used in this study is a part of the overall model currently in use within the Trebišnjica Hydro Information System (the Trebišnjica HIS; Institut za vodoprivredu Jaroslav Černi, 2002). The simulation model is designed to account for the changes of specific parameters (hydrologic input; different scenarios of various users' demand) and assessment of the system behaviour and performance in real operational conditions. The case study area was represented as a system with various components, which simulate the natural flow pattern and artificially created water flows. The natural water flow relevant to the modelling process includes: precipitation and its transformation into the karst inflow; surface water flow; flow through the porous media; flow transformation in karst plains (poljes) and evaporation from the water surface. Gamma transfer functions were used to model transformation of precipitation into the karstic inflow, surface water flow and flow through the porous medium.

Water flows, modified by the man-made (existing or planned) project structures covered by the modelling process, include: routing by reservoirs; dam overflow; flow through dam bottom outlets; seepage through the dam; flow through water tunnels and open canals; flow through turbines and generated power in hydroelectric power plants; flow through pumps and power consumption in pumping stations; water abstraction by users. A schematic representation of the main components concerning the transformation of the precipitation into the various types of flows in the Bregava River system is given in Figure 4.

Figure 4. System decomposition in space for the black-box/transfer function model 
Essentially the Bregava River system comprises two types of entities, nodes and links. The modelling consists of generation of the results according to a functional scheme based on predefined rules of water distribution between the various entities. The nodes represent the model components to which the continuity equation applies. They are merging points of one or more incoming or outgoing links. The following types of nodes are distinguished: karst drainage area; karst plain; reservoir; overflow; bottom outlet; junction; hydroelectric power plant; discharge gully; irrigation intake; water supply; thermal power plant; pumping station and other kinds of outflow. A particular group of nodes is comprised of those from which water invariably leaves the system, while other nodes may be sub-divided into those that have a water demand and those that meet and/or transmit the demand. There are specific parameters that describe the behaviour of each node type.

The links are model components to which the flow equation applies that transform the inflow hydrograph into the outflow hydrograph of the considered link. Links are also used to transmit user demand. Water flows from the inflow node to the outflow node through a link. The system breakdown into entities distinguishes between the following types of the links: karst inflow; surface water flow; groundwater flow; tunnel; direct link (flow without transformation); seepage; evaporation; abstraction for irrigation, water supply and thermal power plant. There are specific parameters that describe the behaviour of each link type, with exception of the simple ones that are by nature direct.

\subsubsection{The conceptual model}


This model was built with the intent to be as simple as possible: The system was simplified by grouping together several of its components and simultaneously using simplified conceptual dynamics of the system. The main objectives of this modelling approach are: (a) to investigate whether simple mechanisms can describe in a satisfactory manner the system behaviour; (b) to identify essentials and discard details in the system dynamics, and (c) to identify sets of parameters for which the system behaviour is described well. As the model, after its calibration, turned out to give sufficient approximation of the system behaviour, it was used for an assessment of the impacts of certain future management conditions. This was done by incorporating the management rules into the model operation, in addition to the natural system dynamics.

The K Sim ${ }^{2}$ model, which stands for Karst Simulation Simplified Model, was built especially for the particular case study based on the specific structure and peculiarities of the hydrosystem studied. It was based on a general experience of the behaviour of karstic systems in Greece (Koutsoyiannis et al., 2001; Rozos et al., 2004).

The schematisation of the hydrosystem, shown in Figure 5, includes the following water storage components:

- A soil moisture reservoir that represents all soil-water processes in the Trebišnjica and Bregava river catchments.

- A single hypothetical polje that merges the Dabarsko and Fatničko polje system, which are connected directly to each other and to the Trebišnjica and Bregava rivers. All other poljes of the wider area (Gatačko, Bilećko, Lukovačko), which are not directly linked to the Bregava river, are not modelled explicitly.

- A groundwater reservoir near the springs discharging to the Bregava river. 
Figure 5. Schematic of the conceptual model.

Based on the above described storage components the following transformations of water quantities are assumed, which are also depicted in Figure 5 with the numbering shown in the following points:

1. Rainfall: With respect to runoff from rainfall, three types of surface are assumed: Impervious areas, pervious areas with soil cover and water areas (poljes); the first two are assumed constant in time whereas the third is assumed to vary depending on the water elevation in the polje.

2. Direct flow: Rainfall falling on impervious areas is directed towards either the polje system (2a) or the Bregava River (2b). The amount of this flow is determined by the relevant areas F2a and F2b, which are assumed constant but unknown (model parameters).

3. Evapotranspiration: Rain falling onto pervious areas (covered by soil) is evaporated or transpired at a rate that does not exceed the rate of potential evapotranspiration.

4. Quick flow: If rainfall is higher than potential evapotranspiration, then the excess water is stored in the soil moisture reservoir, until this reservoir reaches its capacity $K$, which is assumed constant and unknown (model parameter). Rainfall higher than the amount that can be stored is transformed to quick flow. This is directed towards either the polje system (4a) or the Bregava River (4b). The amount of this flow is determined by the relevant areas F4a and F4b, which are assumed constant but unknown (model parameters). 
5. Slow flow to polje system: When the soil moisture reservoir is not empty, an amount proportional to the stored water $S$ is leaked from it and directed to the polje system following groundwater paths. The amount of leakage, if expressed as volume per unit area, is $k S \Delta t$, where $\Delta t$ is the time step (chosen to be one day for all simulations) and $k$ a constant parameter. Thus, the total volume directed to the polje system is determined by the relevant area F5 which does not necessarily coincide with F4a; F5 is assumed constant and unknown (additional parameter).

6. Slow flow to Bregava River: As in the previous case, an additional amount of leaked water is directed to Bregava. The volume per unit area equals that in point 5 and thus the total volume is determined by the relevant area F6 which does not necessarily coincide with F4b. In addition, the sum of areas F5 + F6 does not necessarily equal the sum F4a $+\mathrm{F} 4 \mathrm{~b}$ as some of the leaked water may be directed to other neighbouring catchments. F6 is assumed constant and unknown (additional parameter).

7. Leakage of polje system to Bregava: From both the Dabarsko and Fatničko poljes, water can leak and is directed towards the Bregava River (e.g. through a series of sinkholes in both Dabarsko and Fatničko). All these paths are modelled as a single "conduit" which conveys water from the polje system to Bregava. The water leaked from the polje to this conduit is assumed to depend on the storage in the polje system. Specifically, the amount of this water is assumed to be $f_{7}(V) \Delta t$, where $V$ is the volume of water stored in the polje system and $f_{7}(V)$ is a function whose mathematical form is assumed to be a three-parameter logistic curve, reaching a saturation value for high $V$.

8. Leakage of polje system to Trebišnjica: Another amount of water stored in the polje system leaks towards the Trebišnjica River via sinkholes mainly in Fatničko 
Polje. These sinkholes are modelled as a single hole. Again, the water leaked from the polje to this hole is assumed to depend on the storage in the polje system, $f_{8}(V) \Delta \mathrm{t}$, where $f_{8}(V)$ is a function with mathematical form similar to that of $f_{7}(V)$.

9. Evaporation from polje: The total volume of evaporation is determined directly in each simulation step, given the potential evapotranspiration and the storage $V$, which also determines the area $A$, through the elevation-area-volume curves.

10. Spring discharge: The karstic springs discharging to the Bregava River are modelled as an outlet from the groundwater storage. The volume of water depends on the groundwater reservoir storage $G$ and is given as $f_{10}(G) \Delta t$.

11. River flow: The Bregava river flow is the sum of the spring discharge (10) and the direct flow (2b).

12. Diversion tunnel flow: When the model is run for the future managed conditions, a regulated discharge is assumed through the FP-BR tunnel. The discharge in this reservoir is determined by the tunnel discharge capacity and the regulation rules followed. Both these depend on the water level at the polje system (assuming this corresponds to the Dabarsko Polje water level).

Both direct flow and quick flow are assumed to arrive either to the polje system (2a, 4a) or to Bregava River $(2 b, 4 b)$ without any time lag. In contrast, for each of the groundwater fluxes $(5,6,7)$, in addition to the lag time due to the residence in the relevant reservoir, which is indirectly determined in simulation, another constant lag of one day is assumed to account for the time it takes water to move along the relevant groundwater path. The one day lag was determined by inspecting flow data series during flood events, rather than by the optimization procedure. The system dynamics are 
described by the continuity equations at all nodes of the hydrosystem schematisation, shown in Figure 5, and all functions and rules described analytically in the above points.

\subsection{Model comparison}

A qualitative comparison of model structural features is shown in Figure 6. The quasiphysically based model (3DNet) is the one attempting to more consistently represent physical processes, in that it makes use of physical structures (pipes and reservoirs) as building blocks of the model structure, but this results in an increase in complexity, whereas the conceptual $\left(\mathrm{K} \mathrm{Sim}^{2}\right)$ model is the simplest and loosest, in terms of description of the natural processes, but is also the one where the most sophisticated calibration procedure (automatic nonlinear optimisation) was possible (owing to its simplicity and exceptionally short computation time) and was finally used. The features of the black-box, transfer function model (CERNI), place it in between the two other models.

Figure 6. Qualitative comparison of structural features of the three models

\section{Model Calibration}

All models were run using data sets from two distinct periods:

- Period A: 1/1/1961-31/10/1986 which corresponds to natural conditions of the hydrosystem and

- Period B: $1 / 11 / 1986-31 / 12 / 2003$ which corresponds to partly managed conditions as the DP-FP tunnel was operated during that period.

The following two scenarios were selected to assess the impact of the transfer of water from Dabarsko Polje to Fatničko Polje, and from there to the Bileća Reservoir, on the 
flow regime of the Bregava River at the Do station in all modelling approaches: Natural Conditions ( $\mathrm{NC}$; no water transfer), and Managed Conditions (MC; water is transferred from Dabarsko Polje to Fatničko Polje and to the Bileća Reservoir).

\subsection{Quasi-Physically Based Model}

The simple quasi-physically based model was calibrated using data from 1976 to 1986 without a separate validation period. The calibration process involved the following steps:

(a) First the indirect catchment area calibration was performed on the basis of input flow hydrographs (obtained by the UNSAT model) and measured water levels in Dabarsko Polje. Results of the calibration were the dimensions of an equivalent tunnel (the tunnel that simulates all outflows from Dabarsko Polje). In this phase of calibration, measured and simulated water levels in Dabarsko polje were fitted.

(b) The second step was calibration of the direct catchment area of Bregava, whose aquifer was conceptualised as an underground reservoir. The leakage output from the UNSAT model constitutes the input to the reservoir and its capacity was identified through a calibration process, performed by comparing modelled to measured flows at the Do gauge station.

(c) Inflow in the Fatničko Polje was not calibrated, because it was obtained from field data linking measured flows at the gauge station Srdjevići and inflow in the Fatničko Polje. The only parameters that were calibrated are the dimensions of the swallow holes in Fatničko Polje. Two swallow holes exist in the model: one at the bottom of Fatničko Polje, and the other is positioned $10 \mathrm{~m}$ above the bottom (based on the hydrogeological report (ICCI, 2004)). Calibration was performed by comparing simulation results and measured water levels in the Fatničko Polje. 
The detailed quasi-physically based model was calibrated using data from 1976 to 1982 , without having a separate time series for validation. The model's time step was one minute. Such a small step (compared to the one day time step in other models applied in this study) was dictated by the stability criteria of the numerical methods applied for solving the full-dynamic model equations. Furthermore, the spatial discretisation was fairly detailed, with a total of more than one thousand computational cross-sections across the network of tunnels. Consequently, continuous simulation of several year series required significant computational effort (approximately $310^{6}$ computational time steps), which made the application of any automatic calibration procedure impossible. Therefore, model parameters were adjusted in a trial-and-error process, comparing available discharge and level hydrographs with the calculated ones.

\subsection{The Black-Box Hydrologic Model}

The monitoring and measurement data relating to hydro-meteorological occurrences and other information about the system configuration status during Period A were used to calibrate model parameters while Period B was used for validation. The total outflow from the Trebišnjica is considered known within the model parameter calibration process based on existing records. Calibration was performed starting from the topologically most upstream profiles, artificial reservoirs, natural karst fields up to the outlet profiles (water gauging station on the Bregava River) and structures (Bileća Reservoir on the Trebisnjica). The adopted parameter values calibrated along the upstream reach were considered constant when determining the downstream reaches runoff. The criterion for river flow simulation quality assessment in the calibration phase was the achievement of minimal deviation of computed outputs from the values recorded by key data stations of the system in a least squares sense. 
For the considered period of model parameter identification the measured and simulated multi-annual average discharges are respectively 18.4 and $19.2 \mathrm{~m}^{3} / \mathrm{s}$. The difference of $0.8 \mathrm{~m}^{3} / \mathrm{s}$ is $5 \%$ of the multi-annual average discharge of Bregava at the Do gauging station, which is below the accuracy tolerance for hydro-meteorological (measured and processed) data inputs. The discharge duration curves for the Bregava River at the Do gauging station indicate a significant difference between computed and measured discharges in the discharge duration zones of 5-30\% and $35-80 \%$.

\subsection{The Conceptual Model}

As described above, automatic nonlinear optimization was used for the calibration of this model. The objective function in this optimization problem was a combined measure of discrepancies (in a least squares sense) between observed and modelled water levels at polje and discharges at Do. In order for the model parameters to have some physical meaning, their values are generally assumed to lie within certain limits. However, in this case no limits were imposed a priori, and the parameter values were tested a posteriori and found to be physically consistent. The tools used for optimisation are a collection of algorithms that have been developed and become commercially available by Frontline Systems (http://www.solver.com). These include components of classical optimisation techniques, evolutionary techniques and combinations thereof. The classical techniques implement the so called Generalized Reduced Gradient Method (GRG) (Lasdon et al., 1978; Lasdon and Smith, 1992), which has been proven in use over many years as one of the most robust and reliable approaches to solving difficult nonlinear programming problems. 
The model was calibrated and verified for period A, in which the system operates in natural conditions. The period was split into two sub-periods, the calibration sub-period (1961-1980) and the verification sub-period (1981-1986). The results show a satisfactory behaviour of the model in reproducing flow duration curves for both periods (see Figure 7 and ICCI, 2004).

The $\mathrm{K} \mathrm{Sim}^{2}$ model can break down the total water balance of each hydrosystem component into separate portions related to the origin of water. As far as the discharge of Bregava is concerned, the most important indicator of the impact of the future polje regulation is the percent of total water discharged at Bregava that originates from polje under natural conditions (Flux from poljes, denoted by (7) in Figure 5). The higher this percentage is, the higher the impacts. This however has significant uncertainty, related to the uncertainty of parameters. The sensitivity of the model to varying parameters was assessed through different scenarios constructed by performing alternative model fits on the basis of local minima of the objective function.

\section{Results and Discussion}

The goodness of fit of the different modelling approaches is illustrated in Figure 7 in which simulated results are compared with historical observations in terms of duration curves. (For additional comparisons, including the models' performance in reproducing observed discharge and water level time series, the interested reader is referred to ICCI, 2004).

Figure 7. Comparison of simulated natural conditions in the three models 
It can be observed that, given the data limitations and system complexity, all three models have relatively successfully reproduced observed field measurements, with the K $\mathrm{Sim}^{2}$ model providing the closest fit. Contrary to intuition and also to current scientific trends which favour physically based and mathematically complex modelling approaches, the above results indicate that conceptual modelling approaches may yield better results if combined with state-of-the-art optimisation-based calibration tools. That is, the simplicity and the parsimony of parameters of models such as $\mathrm{K} \mathrm{Sim}^{2}$ allow a better understanding of the system under study, better interpretation of the effect and interrelation of the parameters, much faster simulation (which makes uncertainty analysis easier), and finally enable the use of nonlinear optimisation to estimate parameters.

A more efficient and effective calibration procedure sometimes proves to be more important than a detailed description of the physical system. Thus, in typical practical applications, parameter parsimonious conceptual models, with a simple mathematical structure based on empirical hypotheses, may yield better results than physically-based ones. The latter are restrained by the large amount of spatially distributed data required to represent heterogeneity of physical processes and the intrinsically deficient knowledge of the physical system (e.g. geometry of karst) (Rozos et al., 2004). As mentioned earlier, in the quasi-physical approach the system was discretised in a number of tunnels with more than one thousand computational cross-sections, hence the possible number of unknown parameters is indeed large. On the other hand, the predictive power of conceptual models when background conditions differ from observed ones is reduced. Thus, the usage of conceptual models for extrapolation under different conditions should be done with the great care, since significant errors could be made. Figure 8 presents the results of the three models on the effect of the tunnel operation to Bregava (at the 
location of Do station). Again, the recorded flows at Do prior to 1986 are plotted for comparison purposes.

Figure 8. Comparison of simulated managed conditions in the three models

The differences between the three models are very similar to those of Figure 7 and the results all indicate that the relative effect of the tunnel operation on low flows (below 5 $\left.\mathrm{m}^{3} / \mathrm{s}\right)$ is small.

Figure 9 presents a comparison of predicted changes in the duration of events between managed and natural conditions for the three models. The figure illustrates the percentage change, between unmanaged and managed conditions, in the percent of time flows equal to or greater than any given flow are expected to be observed. For example, it can be seen that the maximum expected reduction (given by the 3DNet model) in the duration of flows $\geq 50 \mathrm{~m}^{3} / \mathrm{s}$ under managed conditions is $78 \%$ of what it would be under unmanaged conditions, which in this case corresponds to a difference of $5.5 \%$ in duration, between $7.1 \%$ of time before and $1.6 \%$ of time after management. For flows of $5 \mathrm{~m}^{3} / \mathrm{s}$, reductions in duration range from 3- 20\%, corresponding to X-Y \% of the total flow duration.

It can be observed that while the differences in flow duration curves between the different models are relatively large, the uncertainty related to the effects of management interventions between model predictions is not significant and is equally distributed for all levels of flow. All three models support the conclusion that the effect of the tunnel operation is more pronounced on high flows and is reduced as flows decrease. 
Figure 9. A comparison of predicted changes in the reduction of duration of flows between the different models.

The 3DNet, quasi-physically based model (in both levels of detail in which it was applied) predicts the smallest difference between simulated values for the natural and managed conditions. The particularly small effect of flow diversion predicted by this model can be attributed to the inconsistency between, on the one hand, the model logical basis to describe the physical processes as faithfully as possible and, on the other hand, the data imperfections and the intrinsically deficient description of the system heterogeneity mentioned above.

The CERNI, transfer function model, which is subject to the most significant discrepancies between the field measurements and model results for the natural conditions, also exhibits the most pronounced differences between modelled natural conditions and managed conditions for mean-to-low flows. Even in this case however, the differences between modelled results in natural and managed conditions for low flows, which are of primary interest of this particular study, are relatively small.

Finally, the $\mathrm{K} \mathrm{Sim}^{2}$ conceptual model, which achieved the best fit between observations and model results, suggests some effects from tunnel operation for mean flows (a reduction of the order of $10-15 \%$ of time in the duration of events) and little effect for low flows. The slight decrease of low flows that is observed must be attributed to the general loss of water from the groundwater storage component after the completion of the project and implementation of regulation. It is also observed that the magnitude of the highest flows does not change, but the highest flows become less frequent. 
Specifically, the models agree that:

- The effect of the tunnel operation on very high flows (above $50 \mathrm{~m}^{3} / \mathrm{s}$ ) will be significant (greater than $60 \%$ reduction). This reduction should have a positive impact on flood prevention in Bregava. However, due to the short duration of such events, this should have no significant effect on the water balance of the receiving Neretva River.

- The effect of the tunnel operation on low flows (around $5 \mathrm{~m}^{3} / \mathrm{s}$ ) is not significant (mean reduction of approximately $10 \%$ ). Therefore, the assumption that the tunnel operation will contribute to the drying up of the Bregava River basin, or to the 'desertification' of the area, cannot be supported by this study.

- The effect of the tunnel operation on medium flows (between $10-35 \mathrm{~m}^{3} / \mathrm{s}$ ) is between the other two (mean reduction of approximately $40 \%$ ).

\section{Conclusions}

The present study focused on the Bregava river catchment which, due to the complex karstic natural system, shares resources with the Trebišnjica catchment depending on hydrological and meteorological conditions. The study aimed at assessing the impact of the planned diversion system under the assumption that the whole system will be completed and that the provisions of the design conditions and permits will be strictly implemented.

The results of the study indicates that the system of tunnels from Dabarsko Polje to Fatničko Polje and from Fatničko Polje to Bileċa Reservoir has a favourable effect in reducing flood hazard (especially depth and duration) in these two poljes and thus liberating scarce land resources for agriculture. 
The study has quantified the effect of the diversion of a part of the flood water from Dabarsko Polje to Fatničko Polje and to Bileća Reservoir on the hydrological regime of the Bregava River in the cross section of the hydrometric station Do, by performing three independent analyses. The results obtained by all three methods are generally similar: there seems to be little effect on the magnitude of extremely high flows (over $50 \mathrm{~m}^{3} / \mathrm{s}$ ), while their duration is somewhat reduced. The most pronounced effect (reduction of flow) occurs in the range between $5-50 \mathrm{~m}^{3} / \mathrm{s}$, and the effect is almost negligible for flows lower than $5 \mathrm{~m}^{3} / \mathrm{s}$. The study cannot therefore support the claim that the tunnel Fatničko Polje - Bileća Reservoir will contribute to the drying up of the Bregava River basin, or to the 'desertification' of the area, under assumptions of proper operation.

In terms of modelling it is concluded that in typical practical applications, parameter parsimonious conceptual models, with a simple mathematical structure, may yield better results than physically-based ones, which are restrained by the large amount of spatially distributed data required to represent heterogeneity of physical processes and the intrinsically deficient knowledge of the physical system, particularly if they are combined with state-of-the-art optimisation-based calibration tools. This is not to say however that model formulation, parameterization, and the skill of the modeller do not have a significant impact on simulation accuracy. Both these observations are in line with observations made by Reed et al (2004).

In all, it is suggested that a quantification of the uncertainty of modelling the karstic environment can be achieved by an appropriate, complimentary combination of modelling approaches, a suggestion which supports the growing interest of the scientific 
community in multi-model ensembles as a tool to tackle issues of uncertainty within complex environments.

\section{Acknowledgements}

We wish to acknowledge the financial support of the Energy Financing Team GmbH in developing this work. We would also like to thank two anonymous reviewers for their detailed and supportive comments. 


\section{References}

Albéric, P. (2004). River backflooding into a karst resurgence (Loiret, France). Journal of Hydrology, 286 (1-4), 194-202.

Allen, R., L. Pereira, D. Raes and M. Smith (1998). Crop evapotranspiration - Guidelines for computing crop water requirements - FAO Irrigation and drainage paper 56, FAO - Food and Agriculture Organization of the United Nations, Rome.

Andreo B., Goldscheider N., Vadillo I., Vias J.M., Neukum C., Sinreich M., Jimenez P., Brechenmacher J., Carrasco F., Hotzl H., Perles M.J. and F. Zwahlen (2006). Karst groundwater protection: First application of a Pan-European Approach to vulnerability, hazard and risk mapping in the Sierra de Líbar (Southern Spain); Science of the Total Environment, 357 (1-3), 54-73.

Avdagić, I. (1976). Determing flows in flooded karst poljes by measuring the water level in piezometers and reservoir, Karst Hydrology and Water Resources: Proceedings of the US-Yugoslavian Symposium, Dubrovnik, 1975, Published by Water Resources Publication, Fort Collins, Colorado.

Djordjević S., D. Prodanović and G. A Walters. (2004). Simulation of transcritical flow in pipe/channel networks. ASCE Journal of Hydraulic Engineering, 130(12), 1167-1178.

Djordjević, S., D. Prodanović, and M, Stanić (2003) Urban Hydrology and Drainage - Part 2. Introduction to 3DNet, 34th International Post-Graduate Course on Hydrology, VITUKI, Budapest.

Eisenlohr L, Kiraly L, Bouzelboudjen M, Y. Rossier Y. Numerical simulation as a tool for checking the interpretation of karst spring hydrographs, Journal of Hydrology, 193 (1-4), 306-315

ICCI (2004). Analysis of the effects of water transfer through the tunnel Fatničko Polje - Bileća Reservoir on the hydrologic regime of Bregava River in Bosnia and Herzegovina. C. Maksimovic and C. Makropoulos (eds). Report for Energy Financing Team, London. Available online: http://www.itia.ntua.gr/e/docinfo/627/

Institut za vodoprivredu "Jaroslav Černi” (2002). Hidro-informacioni sistem "Trebišnjica”, Verzija 1.0, Zavod za brane, hidroenergetiku, rudnike I saobraćajnice, Beograd.

Koutsoyiannis, D., A. Efstratiadis, N. Mamassis, I. Nalbantis, and L. Lazaridis, (2001) Hydrological study of reservoir operation, Engineering consultant for the project "Water supply of Heracleio and Agios 
Nicolaos from the Aposelemis dam", Commissioner: Ministry of Environment, Planning and Public Works, Contractor: Aposelemis Joint Venture, Athens, October . (in Greek)

Kovacs A., Perrochet P., Kiraly L. and P.-Y. Jeannin (2005). A quantitative method for the characterization of karst aquifers based on spring hydrograph analysis. Journal of Hydrology, 303, 152-164

Lasdon, L.S. and S. Smith, (1992) Solving Sparse Nonlinear Programs Using GRG, ORSA Journal on Computing, 4(1), 2-15.

Lasdon, L.S., A. Waren, A. Jain and M. Ratner (1978), Design and Testing of a Generalized Reduced Gradient Code for Nonlinear Programming, ACM Transactions on Mathematical Software, 4(1), 34-50.

Milanović, P. (1981). Karst hydrogeology, WRS, Colorado.

Milanović, P. (1986). Influence of the karst spring submergence on the karst aquifer regime, Journal of Hydrology.

Pokrajac, D., Stanić, M. and Lazić, R. (2006) UGROW - a software tool for integrated urban water management, 7th Int. Conf. on Urban Drainage Modelling and 4th Int. Conf. on Water Sensitive Urban Design, Melbourne, V1.485-V1.492.

Prodanović D., S. Djordjević, Č. Maksimović (1998). GIS Assisted Model for Dual Drainage Simulation, Hydroinformatics '98, Copenhagen.

Reed, S., V. Koren, M. Smith, Z. Zhang, F. Moreda, D. Seo and DMIP Participants (2004). Overall distributed model intercomparison project results, Journal of Hydrology, 298, (1-4), 27-60.

Rozos, E., A. Efstratiadis, I. Nalbantis, and D. Koutsoyiannis (2004), Calibration of a semi-distributed model for conjunctive simulation of surface and groundwater flows, Hydrological Sciences Journal, 49(5), 819-842.

Smith, M., K. Georgakakos and X. Liang (2004). The distributed model intercomparison project (DMIP) Journal of Hydrology, 298 (1-4), 1-3

Stanger N., (2000). A viewpoint-based framework for discussing the use of multiple modelling representations. Lecture Notes in Computer Science 1920, 154-167. 
Vias J., M., Andreo B, Perles M.J., Carrasco F, Vadillo I and P. Jimenez (2006). Proposed method for groundwater vulnerability mapping in carbonate (karstic) aquifers: the COP method Hydrogeology Journal $14(6), 912-925$

Wheater, H.S., A.J. Jakeman and K.J. Beven (1993). Progress and directions in rainfall-runoff modelling. In: Modelling Change in Environmental Systems, Ed. A.J. Jakeman, M.B. Beck and M.J. McAleer, Wiley, 101-132. 


\section{List of Figures}

Figure 1. General outline of the area and current level of development of the whole Trebišnjica system. Thick lines are catchment boundaries and arrows indicates main karstic flow routes. Dashed lines represent tunnels, full dots represent springs while half-full dots represent ponors. Hydroelectric stations are marked as a square. The Do station is located upstream from Stolac, close to the catchment boundary.

Figure 2. Base of karstification as underground watershed (Milanović, 1986). (A) Karstified rock mass, (B) dense rock mass below base of karstification

Figure 3. System decomposition in space for the quasi-physically based model

Figure 4. System decomposition in space for the black-box/transfer function model

Figure 5. Schematic of the conceptual model.

Figure 6. Qualitative comparison of structural features of the three models

Figure 7. Comparison of simulated natural conditions in the three models

Figure 8. Comparison of simulated managed conditions in the three models

Figure 9. A comparison of predicted changes in the reduction of duration of flows between the different models. 


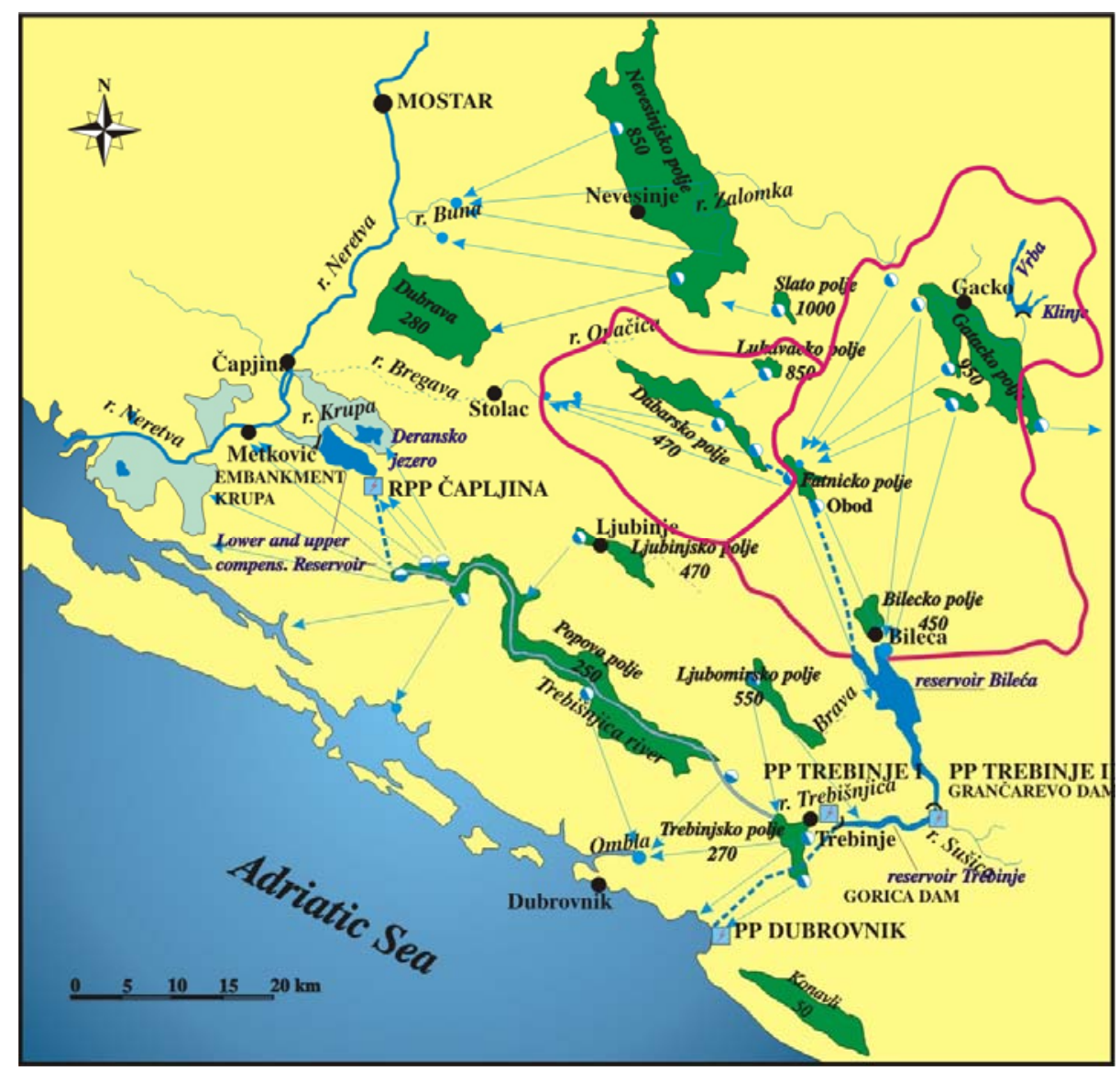

Figure 1. General outline of the area and current level of development of the whole Trebišnjica system.

Thick lines are catchment boundaries and arrows indicate main karstic flow routes. Dashed lines represent tunnels, full dots represent springs while half-full dots represent ponors. Hydroelectric stations are marked as squares. The Do station is located upstream from Stolac, close to the catchment boundary. 


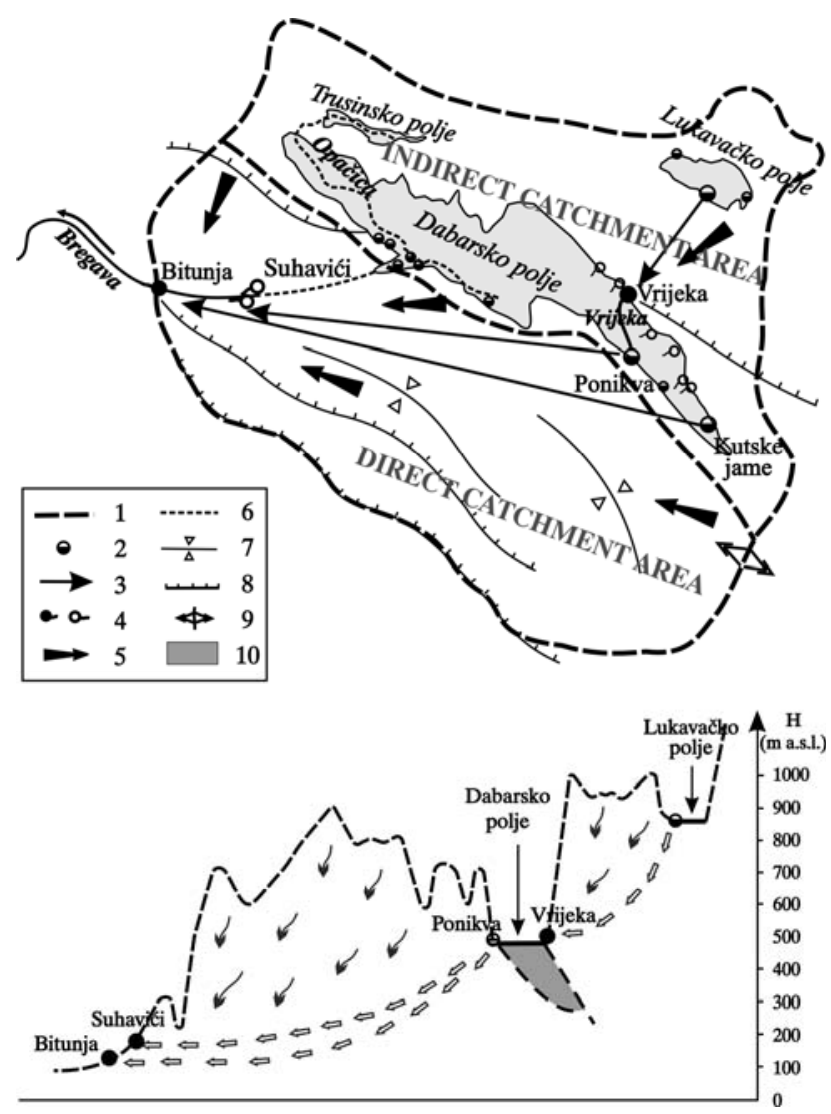

Figure 2. Simplified hydrogeological map of the Bregava source spring drainage area

1. Catchment area, 2. Ponor, 3. Underground communication detected by a dry test, 4. Permanent or intermittent source spring, 5. General direction of underground water circulation, 6. Dry valley, 7. Synclinal axis, 8. Reverse fault, 9. Zone of bifurcation, 10. Impervious tertiary sediments. Source: (Milanović, 1986). 


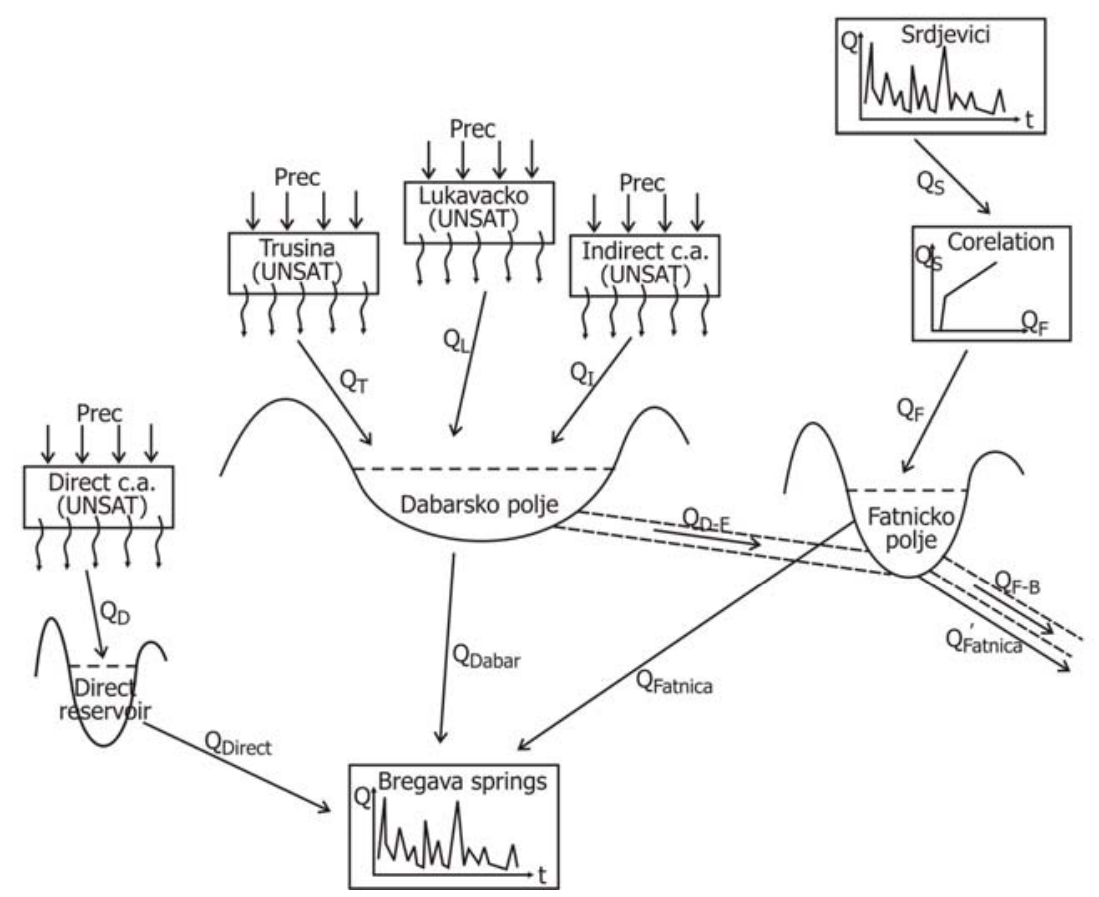

Figure 3. System decomposition in space for the quasi-physically based model 


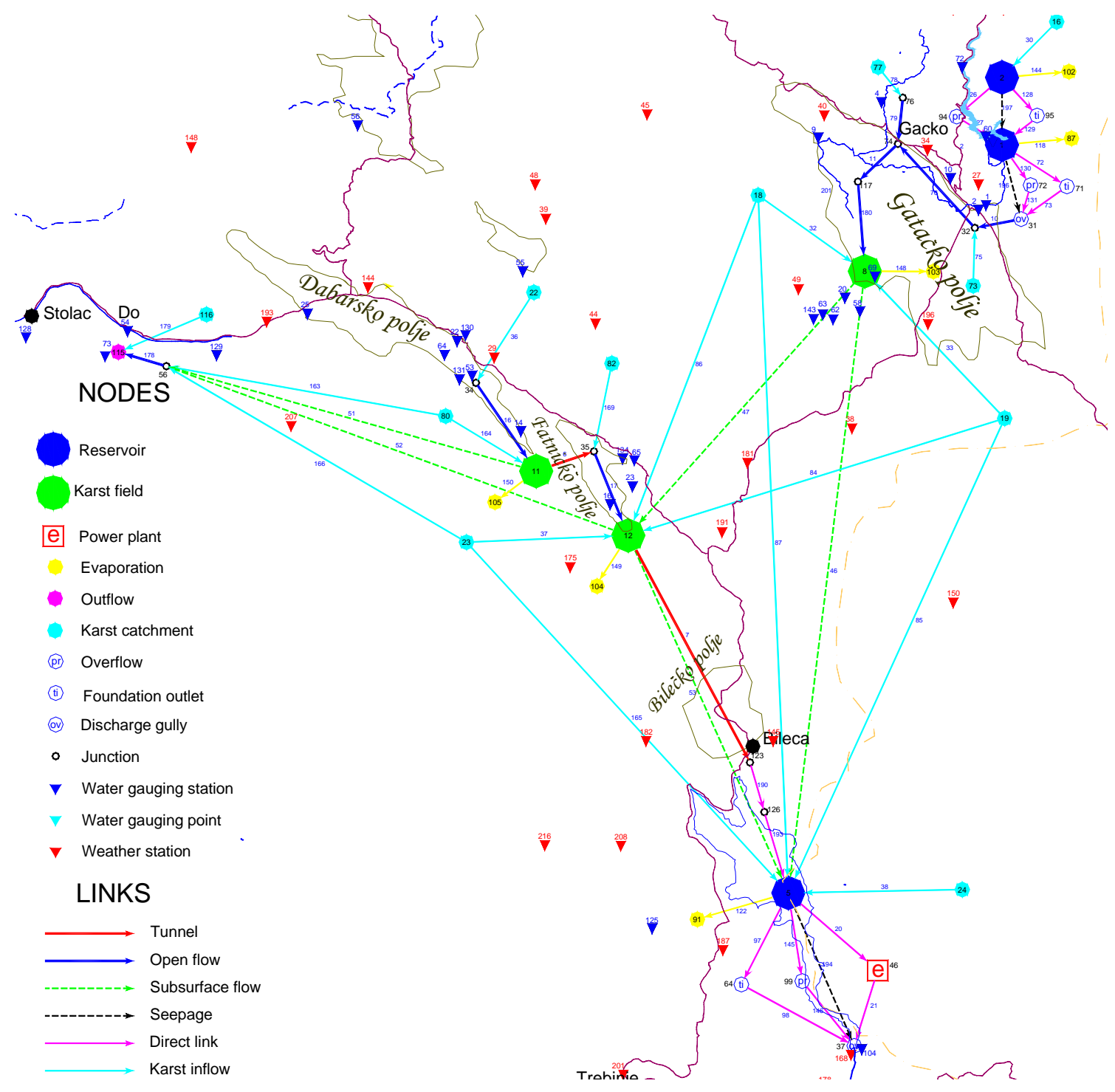

Figure 4. System decomposition in space for the black-box/transfer function model 


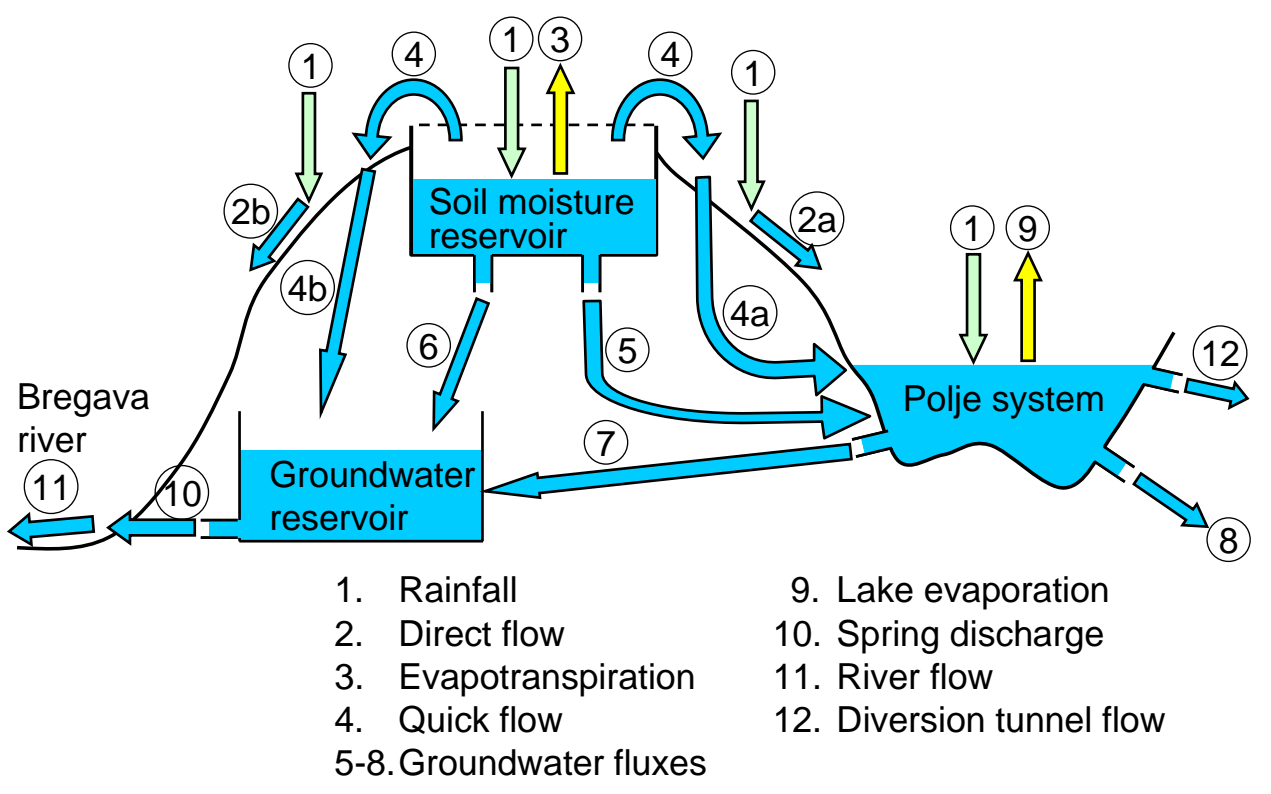

Figure 5. Schematic of the conceptual model. 


\begin{tabular}{|c|c|c|c|c|}
\hline Model feature & Characterisation & 3DNet & CERNI & $\mathrm{K} \mathrm{Sim}^{2}$ \\
\hline $\begin{array}{l}\text { Hydrosystem structure } \\
\text { representation }\end{array}$ & $\begin{array}{l}\text { Detailed } \\
\text { Rough }\end{array}$ & & & \\
\hline $\begin{array}{l}\text { System dynamics } \\
\text { representation }\end{array}$ & $\begin{array}{l}\text { Detailed } \\
\text { Rough }\end{array}$ & & & \\
\hline $\begin{array}{l}\text { Consistency in representation } \\
\text { of physics }\end{array}$ & $\begin{array}{l}\text { Physics-based } \\
\text { Conceptual }\end{array}$ & & & \\
\hline $\begin{array}{l}\text { Complexity of mathematical } \\
\text { model }\end{array}$ & $\begin{array}{l}\text { Complex } \\
\text { Simple }\end{array}$ & & & \\
\hline Number of parameters used & $\begin{array}{l}\text { More } \\
\text { Fewer }\end{array}$ & & & \\
\hline Model calibration procedure & $\begin{array}{l}\text { Sophisticated } \\
\text { Simple statistical }\end{array}$ & & & \\
\hline
\end{tabular}

Figure 6. Qualitative comparison of structural features of the three models 


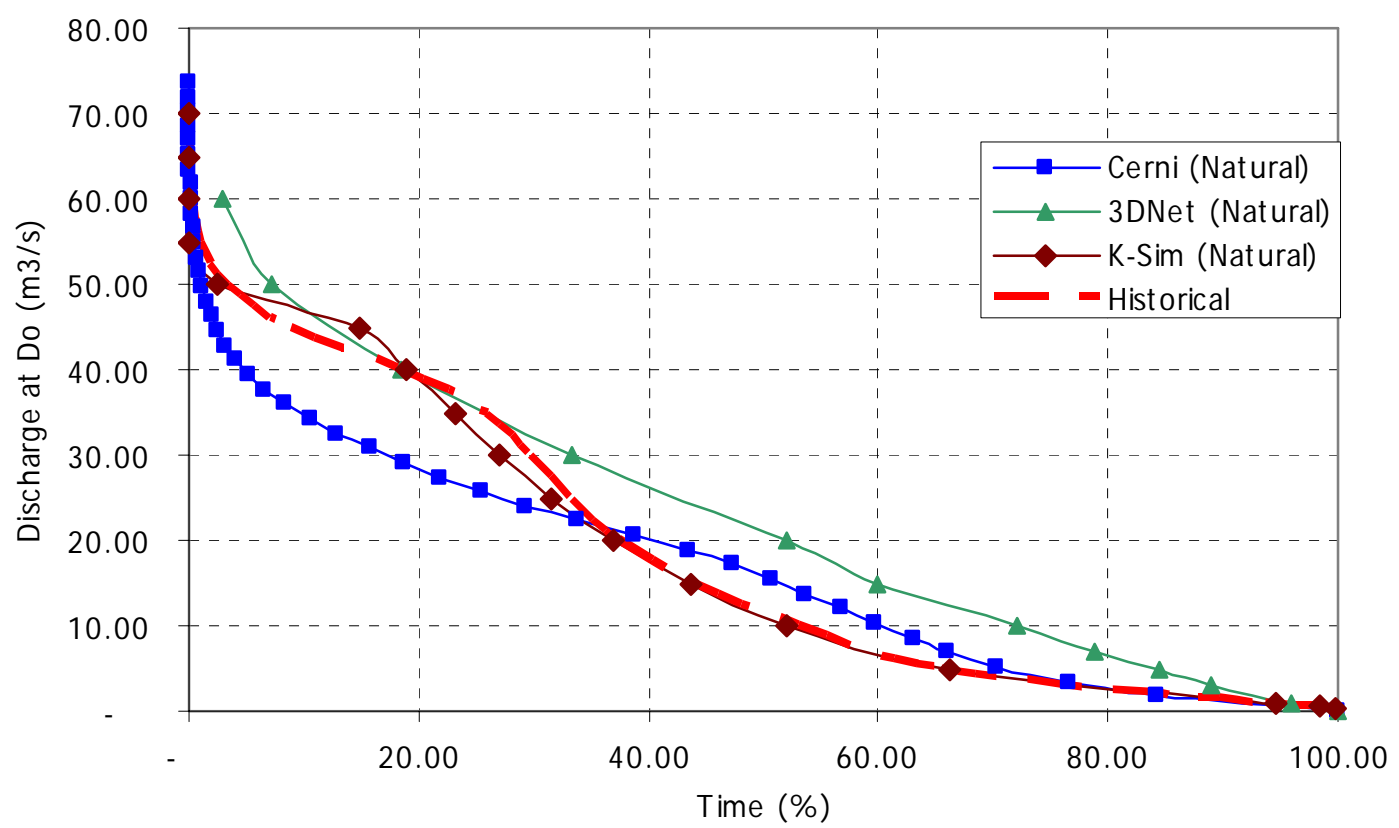

Figure 7. Comparison of simulated natural conditions in the three models 


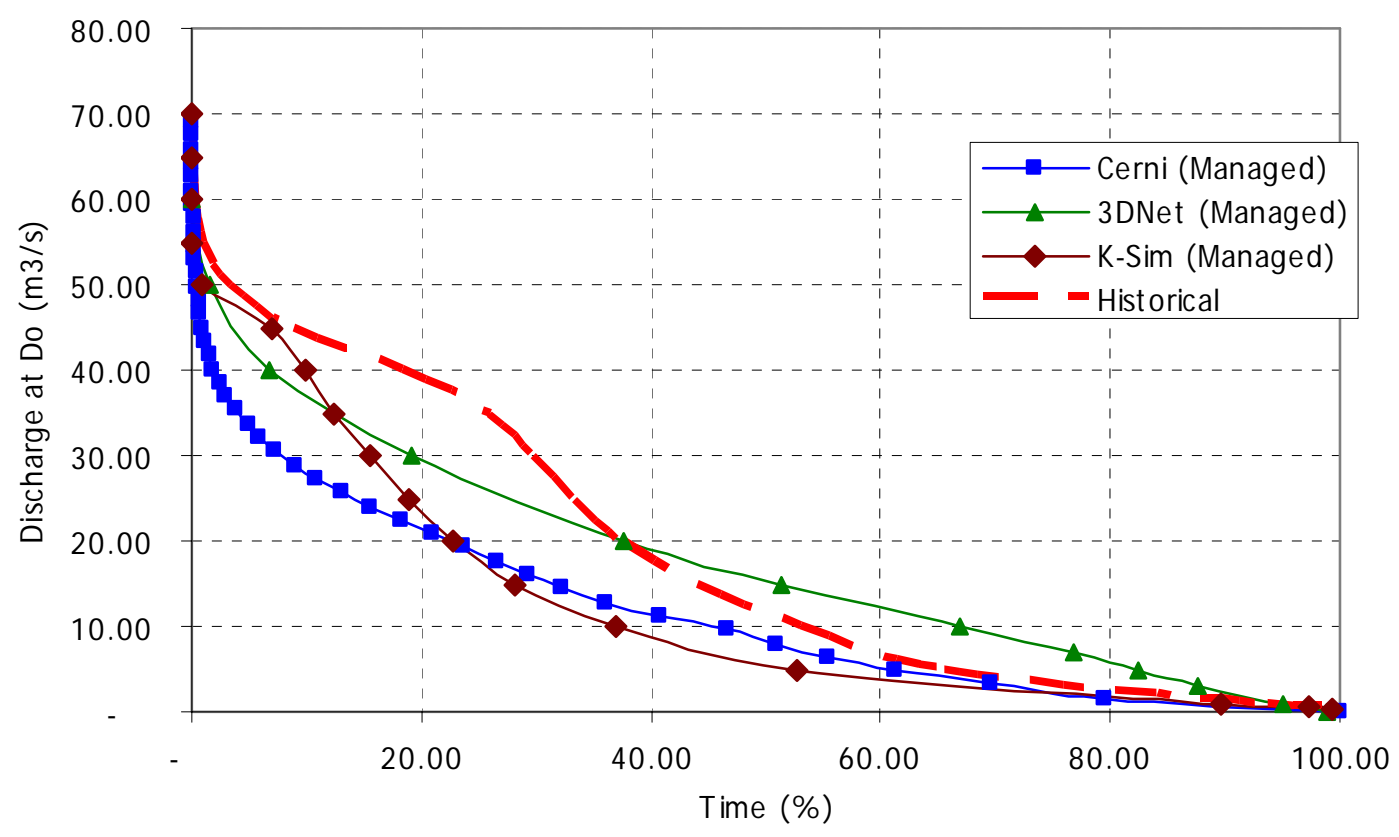

Figure 8. Comparison of simulated managed conditions in the three models 


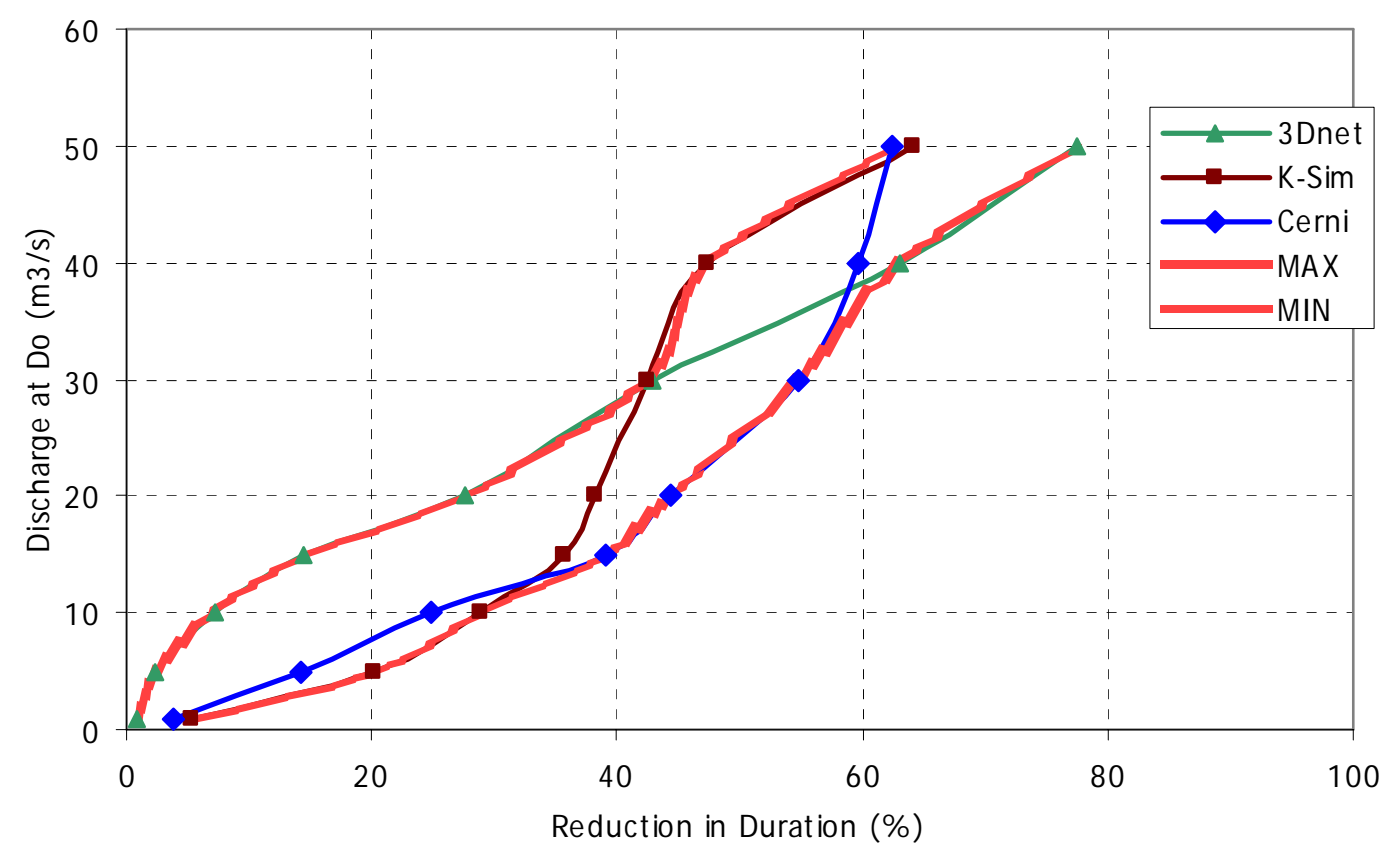

Figure 9. A comparison of predicted changes in the reduction of duration of flows between the different models. 